\title{
Assessing time-varying causality network of ensemble neural spiking activity
}

\author{
Sanggyun Kim ${ }^{1 *}$, Marcelo Aguilar ${ }^{2}$, Todd P Coleman ${ }^{1}$ \\ From Twentieth Annual Computational Neuroscience Meeting: CNS*2011 \\ Stockholm, Sweden. 23-28 July 2011
}

Neurons in many brain regions change their spiking responses and interactions among them to relevant stimuli. Tracking the dynamics of neural system is crucial for understanding how neural systems adapt their responses to relevant biological information. Granger causality [1] has been effectively used to assess directional interactions between continuous neural signals, but it cannot be directly applied to neural spike trains viewed as point processes. Recently, methods that extend Granger's viewpoint to the point process modality have been developed [2], [3] to identify causal interactions between neural spike trains. These methods, however, depend upon stationarity assumptions - which might not be valid when the interactive causal influences themselves are time-varying. We propose a novel probabilistic method for tracking the time-varying causal neural interactions based on sequential prediction of point process models. The time-varying causality from neuron $x$ to $y$ is assessed by the variability of a windowed version of the point process log-likelihood ratio (LLR), where one model incorporates only the past $y$ and the other incorporates the past of both $x$ and $y$. The proposed method successfully tracks the time-varying causal network in simulated data, and when applied to real neural data recorded in the rat insular cortex, it identifies the change of causal relationships between neurons to a relevant behavioral stimulus (see Figure 1).

\section{Conclusions}

The time-varying causal connectivity between neurons was assessed based on the instantaneous point process LLR calculated using the sequential probability assignment method. The proposed framework can be easily

\footnotetext{
* Correspondence: sgkim1@illinois.edu

'Department of Electrical and Computer Engineering, University of Illinois at Urbana-Champaign, Urbana, Illinois 61801, USA

Full list of author information is available at the end of the article
}

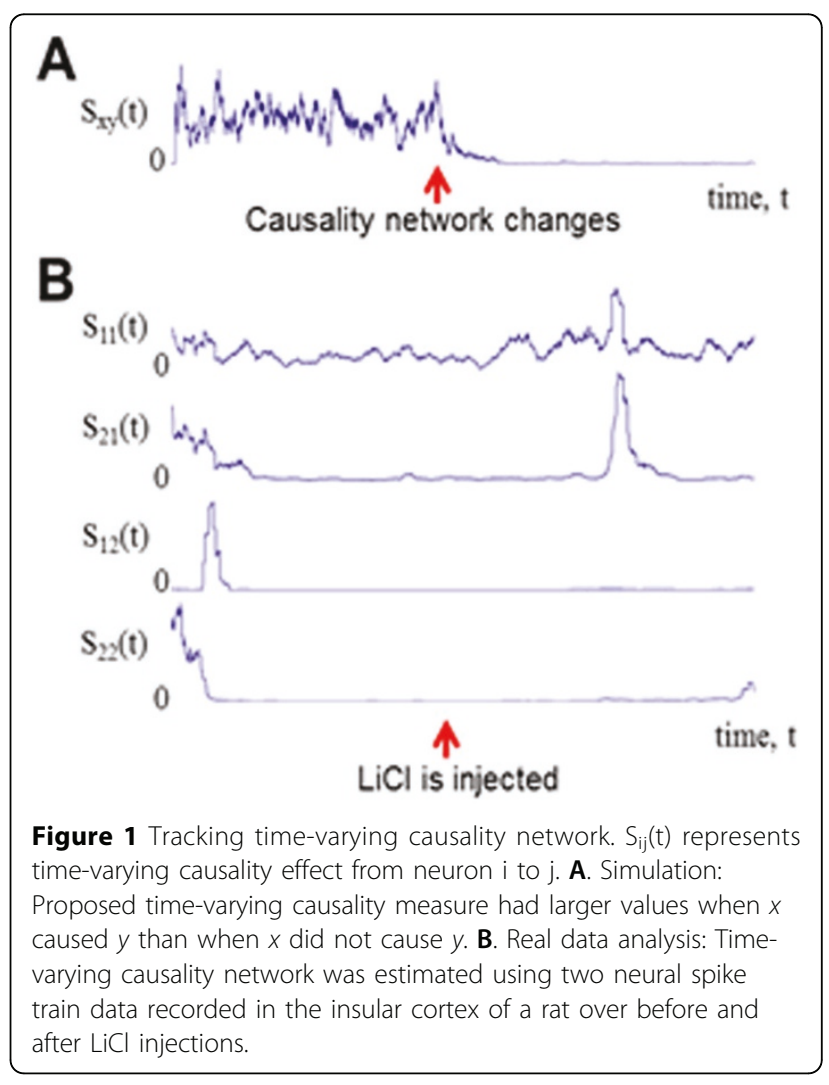

extended to different modalities of neural signals using general exponential family of distributions.

\section{Author details \\ 'Department of Electrical and Computer Engineering, University of Illinois at Urbana-Champaign, Urbana, Illinois 61801, USA. ${ }^{2}$ Department of Biological} Sciences, Pontifical Catholic University of Chile, Santiago, Chile.

Published: 18 July 2011

(c) 2011 Kim et al; licensee BioMed Central Ltd. This is an open access article distributed under the terms of the Creative Commons 


\section{References}

1. Granger C: Investigating causal relations by econometric models and cross-spectral methods. Econometrica 1969, 37:424-438.

2. Kim S, Putrino D, Ghosh S, Brown EN: A Granger causality measure for point process models of ensemble neural spiking activity. PLoS Comput Biol.

3. Quinn C, Coleman TP, Kiyavash NG, Hatsopoulos NG: Estimating the directed information to infer causal relationships in ensemble neural spike train recordings. J Comput Neurosci 2011, 30:17-44

doi:10.1186/1471-2202-12-S1-P43

Cite this article as: Kim et al:: Assessing time-varying causality network of ensemble neural spiking activity. BMC Neuroscience 2011 12(Suppl 1): P43.

Submit your next manuscript to BioMed Central and take full advantage of:

- Convenient online submission

- Thorough peer review

- No space constraints or color figure charges

- Immediate publication on acceptance

- Inclusion in PubMed, CAS, Scopus and Google Scholar

- Research which is freely available for redistribution

Submit your manuscript at www.biomedcentral.com/submit 